\title{
Effect of operating parameters on a Centrifugal Partition Chromatography separation
}

\author{
Norbert Fumat, Alain Berthod, Karine Faure*
}

\author{
Univ Lyon, CNRS, Université Claude Bernard Lyon 1, Ens de Lyon, Institut des Sciences \\ Analytiques, UMR 5280, 5 rue de la Doua, F-6910o Villeurbanne, France
}

\begin{abstract}
Centrifugal partition chromatography (CPC) is the branch of countercurrent chromatography (CCC) that works with single axis hydrostatic columns with rotary seals. The hydrodynamic of the liquid stationary phase-liquid mobile phase equilibrium in the CPC chambers has been studied theoretically and with specially designed CPC columns. In this work, we selected a simple analytical separation (no loading study) of three test solutes, coccine red, coumarin and carvone, with a commonly used heptane/ethyl acetate/methanol/water 1:1:1:1 v/v biphasic liquid system and two different rotors: a commercially available $30-\mathrm{mL} \mathrm{CPC} \mathrm{instrument} \mathrm{and} \mathrm{a} 80-\mathrm{mL}$ prototype rotor designed for productivity. We fully studied this separation in many possible practical operating conditions of the two rotors, aiming at a generic column characterization. The rotor rotation was varied between 1000 and $2800 \mathrm{rpm}$, the aqueous mobile phase flow rate was varied between 1 and 22 $\mathrm{mL} / \mathrm{min}$ with the $30-\mathrm{mL}$ rotor and 10 and $55 \mathrm{~mL} / \mathrm{min}$ with the $80-\mathrm{mL}$ rotor, the upper limits being mechanical constraints and some liquid stationary phase remaining in the rotor. The variations of $S f$, the volume ratio of stationary phase in the rotor, were studied versus mobile phase flow rate and rotor rotation speed. A maximum mobile phase linear velocity was found to depend on the centrifugal field for the 30-mL rotor. This maximum velocity was not observed with the 80-mL rotor. Studying the changes in coumarin and carvone peak efficiencies, it is established that the number of cells required to make one theoretical plate, i.e. one chromatographic exchange, is minimized at maximal rotation speed and, to a lesser extent, at high mobile phase flow rate (or linear velocity). Considering the throughput, there is evidence of an optimal flow rate depending on the rotor rotation that is not necessarily the highest possible.
\end{abstract}

\section{Keywords}

Centrifugal partition chromatography, countercurrent chromatography, stationary phase retention, mobile phase velocity, efficiency, productivity.

\section{Highlights}

- Practical study of stationary phase retention versus mobile phase flow rate,

- Effect of the centrifugal field strength (rotor rotation),

- Effect of flow rate and field strength on peak efficiencies,

- Optimization of preparative productivity.

\footnotetext{
* To whom all correspondance should be sent: karine.faure@,isa-lyon.fr
} 


\section{Introduction}

Countercurrent chromatography (CCC) is a separation technique that uses two liquid phases without solid support. Two main advantages compensate for the need of a centrifugal field to hold the liquid stationary phase steady while the liquid mobile phase percolates through it [1-3]. The first advantage is the high load possible in the volume of the liquid stationary phase compared to the overload problems commonly encountered with saturated surfaces of solid stationary phases. The second advantage is that CCC offers a huge selectivity panel since chemists can finely tune their solvent system to the sample to be purified. Solvent selection in CCC is crucial since it is selecting at the same time the stationary phase, which would be the column in other chromatographic techniques, and the mobile phase. Any composition change in one liquid phase may induce a change in the other liquid phase. To help in the delicate and time-consuming step of liquid system selection in CCC, databases now gather the literature worldwide experience $[4,5]$.

Two types of CCC columns were made commercially available: i) the hydrodynamic CCC columns with rotating coils of simple tubing and ii) the hydrostatic $\mathrm{CCC}$ columns called Centrifugal Partition Chromatographs (CPC) with disks of interconnected cells. A great deal of efforts have been carried out since the past 10 years by suppliers to provide robust and efficient technologies, for both hydrodynamic CCC and hydrostatic CPC instruments. However, it is still not rare to encounter users complaining about long runs (hours) and broad peaks when working with CCC columns. This common observation comes from the fact that, while spending days to work on selectivity finely tuning the liquid system for the purification, the instrument operating parameters are overlooked and not optimized, leading to a false image of CCC and discouraging beginners. In 2005, Ito provided general rules for hydrodynamic CCC instruments [6]. In this work, we would like to study how the CPC operating parameters are related to throughput with a simple analytical separation. The numerous problems associated with large mass and/or volume injections were not examined.

In CPC, the two main concerns are i) stationary phase retention, that influences retention volumes and hence resolution as well as time- and solvent-consumption, and ii) band broadening, related to peak sharpness, peak overlaps, resolution and final purity of the collected fractions. A special parameter, $S f$, has to be introduced in CCC which describes variable stationary phase volumes [1-3]. $S f$ is defined as the ratio of $V_{S}$, the volume of stationary phase over $V_{C}$, the column volume. Two groups have extensively worked on $S f$ and band broadening in CPC. The group of Marchal from St Nazaire (France) developed an impressive work on mass transfer and flow regimes based on visualization using a specially designed CPC instrument with a transparent disk. They modeled mass transfer and efficiencies and proposed improvements of cell design [7-9]. Introducing the concept of height of a transfer unit (HTU), they established that increasing both centrifugal field and flow rate improved mixing, interfacial area and hence mass transfer. Schembecker at Dortmund (Germany) also used flow visualization to study flow patterns in a transparent disk CPC working with various solvent systems and comparing different cell designs. This group pointed out the impact of phase viscosity on stationary phase retention [10-12]. While suggesting improvements on cell design and a preferential selection of solvent systems with low interfacial tension, their advice on operating parameters is limited to the use of maximal rotation speed. 
While these two groups provided a work of tremendous quality in understanding the effect of operating parameters on hydrodynamics, their main purpose remained CPC cell engineering and their tools, such as flow visualization instruments and mathematical models, seem only accessible to experts.

Our purpose is to confirm the general trends that were previously exposed and practically observed in CPC practice. The systematic study is based on a simple separation of standards working with two different commercial CPC instruments at low concentration. The influence of the mobile phase flow rate and rotor rotation speed (centrifugal field) on stationary phase retention, band broadening, resolution and throughput will be experimentally studied with these two different rotors and the same test solute sample (low concentration) and liquid system.

\section{Experimental section}

\subsection{Apparatus}

The frame instrument is a hydrostatic apparatus model, FCPC-A from Kromaton Rousselet-Robatel (Annonay, France) including safety casing, motor with its electronic regulation and a fan with a liquid cooling circulation. Its central shaft can receive interchangeable columns (or rotors). Two 32-cm diameter rotors were used. The first one is a commercially available rotor. It had a measured exact volume of $33.25 \mathrm{~mL}$ with 832 twincells with a number-eight shape at an average distance of $10 \mathrm{~cm}$ from the central axis of rotation. The Kromaton Company proposed to test a prototype rotor of larger volume designed for preparative purification at high flow rates. The prototype rotor has an exact volume measured as $83.4 \mathrm{~mL}$ with 406 twin-cells also at an average distance of $10 \mathrm{~cm}$ of the central axis. The exact shape of the cell is proprietary. The rotor could fit into the FCPC-A frame. All known characteristics of the two rotors are listed in Table 1. For convenience, the analytical and preparative rotors will be referred as the $30-\mathrm{mL}$ and $80-\mathrm{mL}$ rotors, respectively.

A refrigerated circulator F10-C Julabo (Colmar, France) was used to cool down the CPC instrument by flowing chilled water in the dedicated lines of the FCPC-A frame. A Puriflash integrated system from Interchim (Montluçon, France) was used for solvent delivery, injection and detection. This equipment is the assembly of a quaternary pump (flow rate from 1 to $60 \mathrm{~mL} / \mathrm{min}$, maximal pressure $200 \mathrm{bar}$ ), an automatic loop injection valve fitted with a $10 \mathrm{~mL}$ sample loop, a UV/VIS dual wavelength spectrophotometer set at $254 \mathrm{~nm}$ and $280 \mathrm{~nm}$ and a fraction collector. An integrated computer with touch-screen allows for full apparatus control and data acquisition.

The volume of connecting tubing or extra-rotor volume has been measured to be $4.9 \mathrm{~mL}$ from injection to detection points.

\subsection{Phase system and test solutes}


All reagents were of analytical grade. Methanol, heptane and ethyl acetate as well as the three model solutes new coccine red, coumarin and carvone were purchased from SigmaAldrich (Saint-Quentin Fallavier, France).

The selected solvent system on all experiments was the heptane/ethyl acetate/methanol/water 1:1:1:1 (v/v) mixture also referred as Arizona $\mathrm{N}$ or HEMWat zero system [13]. After full equilibration, one liter of this solvent system splits at room temperature in two phases: $412 \mathrm{~mL}$ of the upper phase with heptane, ethyl acetate, methanol and water composition 62.5/34.4/2.6/0.5\% v/v, density $0.752 \mathrm{~g} / \mathrm{mL}$, viscosity $0.40 \mathrm{cP}$ or $\mathrm{mPa} . \mathrm{s}$, and $588 \mathrm{~mL}$ of lower phase with $0.1 / 18.3 / 39.9 / 41.7 \% \mathrm{v} / \mathrm{v}$, density $0.898 \mathrm{~g} / \mathrm{mL}$, viscosity $1.45 \mathrm{cP}$ or mPa.s. The phase density difference is $0.146 \mathrm{~g} / \mathrm{mL}$ and the interfacial tension is $2.5 \mathrm{mN} / \mathrm{m}[11,13]$. With the relatively polar test solutes selected, this solvent system was used in the reversed phase mode i.e. the mobile phase was the aqueous polar lower phase flown in the descending mode. The liquid stationary phase was the less polar organic upper phase.

The test solutes selected to carry on the study were picked up from the solute list proposed by Friesen and Pauli $[14,15]$. The selection was based on UV absorptivity and a wide polarity range implying a large range of partition coefficients in very different liquid systems. New coccine red is a charged compound that did not partition in the selected solvent system being exclusively located in the aqueous lower phase coloring it red. It was therefore used as a non-retained marker for mobile phase volume determination. Coumarin and carvone were selected with partition coefficient of $1.3 \pm 0.3$ and $7.5 \pm 0.5$, respectively, in the 1:1:1:1 Arizona N or HEMWat o system. Coumarin spends as much time in the stationary organic phase as in the aqueous mobile phase of this system. Carvone favors the less polar stationary phase of the selected liquid system: it is a compound that exhibits a high retention factor in the selected solvent system. Resolution and efficiency will be studied with coumarin and carvone even at very low stationary phase retention volume ratio.

\subsection{Experimental procedure}

The rotor to be used, either the 30-mL standard rotor or the $80-\mathrm{mL}$ prototype rotor, was installed inside the FCPC-A frame, connected to the upper and lower rotary seals and rinsed first with the lower phase and next with the upper phase of the HEMWat o (or AZ N) solvent system. The cooling unit was set to circulate water at $15^{\circ} \mathrm{C}$ to remove calories out of the FCPC-A chamber whose temperature would otherwise rise due to heat generated by rotary seal rotation. With the rotor spinning at 2500 rpm, the FCPC-A chamber temperature was monitored stable at $21^{\circ} \mathrm{C}$.

For a given experiment, the rotor spinning at $600 \mathrm{rpm}$ is entirely filled with the upper stationary phase at $5 \mathrm{~mL} / \mathrm{min}$ (30-mL rotor) or $15 \mathrm{~mL} / \mathrm{min}$ (80-mL rotor) in the descending mode. Then the rotation is set up at the speed needed for the experiment. Table 2 indicates the relationship between centrifugal fields and rotation speeds for the two rotors with cells at an average $10 \mathrm{~cm}$ distance from the central axis. After the working rotational speed is stabilized (less than $2 \mathrm{~min}$ ), the lower aqueous mobile phase is pumped through the stationary phase in the descending mode. The driving pressure is monitored increasing as more cells are equilibrated and only upper organic phase is collected at the column exit. As the pressure reaches its maximal value during equilibration, the maximum pressure security electronic switch is set at 70 bars to protect the rotary seals. The equilibrium is reached when the driving pressure stabilizes and only the lower mobile phase is collected exiting the 
column and the UV signals (254 and $280 \mathrm{~nm}$ ) stabilize on their respective baseline. In our solvent system, the existence of a void volume marker allowed the calculation of the stationary phase volume. But it is also possible to collect the displaced stationary phase volume and to deduce from this collected phase the volume of stationary phase remaining in the column. This method is however less accurate than the void volume marker. All extra volumes have to be carefully taken into account, especially that from the pumping system to the injection point and from the detection cell to the collection point.

Analytical injections consisted in the injection of a sample volume not higher than $2 \%$ column volume and a low sample concentration giving a signal/noise ratio $\geq 10$. In this way, the peaks have Gaussian appearance (Fig. 1). The analytical conditions were $0.5 \mathrm{mg} / \mathrm{mL}$ new coccine red, $1.5 \mathrm{mg} / \mathrm{mL}$ coumarin and $2.5 \mathrm{mg} / \mathrm{mL}$ carvone with an injection volume of 0.5 $\mathrm{mL}$ corresponding to $1.5 \%$ and $0.6 \%$ of the $30-\mathrm{mL}$ and $80-\mathrm{mL}$ rotors, respectively. In these injection conditions, the contribution of the dispersion in injection loop can be neglected in regards to chromatographic dispersion.

\subsection{Data acquisition and theory}

The stationary phase volume $\left(V_{S}\right)$ is deduced using the mobile phase volume $\left(V_{M}\right)$, experimentally obtained as the unretained new coccine red elution volume. This experimental mobile phase volume includes the mobile phase contained in the rotor and the mobile phase contained in the extra-column volume $(4.9 \mathrm{~mL}) . S f$, the stationary phase retention volume ratio discussed in this study, corresponds to the ratio of $V_{S}$, the amount of stationary phase contained in the rotor, over $V_{C}$, the rotor volume. Since it is assumed that the chromatographic extra-volume (injection loop, connecting tubing and detection cell) are entirely filled with mobile phase, the $V_{S}$ volume will be taken as $V_{S}=\left(V_{C}+4.9\right)-V_{M}^{\prime}$, with $V_{C}$ being either 33.25 (30-mL rotor) or 83.4 (80-mL rotor) and $V_{M}^{\prime}$ being the coccine red retention volume.

The Azur software (Datalys, France) provides peak retention time, peak width at halfheight expressed in time unit. The peak standard deviation, $\sigma_{o b s}$ is back calculated through eq. 1 , where $w_{o .5}$ is the peak width at half height.

$$
\sigma_{o b s}=\frac{w_{0.5}}{2.354} \quad \text { eq. } 1
$$

$\sigma_{o b s}$ can also be related to the peak width expressed as $2 \sigma_{o b s}$ at $60 \%$ of peak height or $4 \sigma_{o b s}$ at peak base when the peak is fully Gaussian.

The peak standard deviation $\sigma_{\text {tubing }}$ occurring in connecting tubing is quantified using the same equation when replacing the rotor by a zero-dead-volume connector and injecting a tracer.

In the Gauss theory, the peak standard deviation $\sigma$ relates to the peak width (eq 1), while the peak variance $\sigma^{2}$ relates to the physical phenomenon that cause this band broadening. Since the solute band spreads through various dispersion effects, the variances $\sigma^{2}$ are additives. Hence, the dispersion due to the rotor $\sigma^{2}$ rotor, is deduced from the variance obtained from the overall separation, $\sigma^{2}$ obs, minus $\sigma^{2}$ tubing, the tubing variance (eq. 2).

$$
\sigma^{2} \text { rotor }=\sigma^{2} \text { obs }-\sigma^{2} \text { tubing }
$$

eq. 2 
The effective number of theoretical plate generated in the rotor is hence calculated through eq. 3 .

$$
N_{\text {effective }}=\frac{\left(V_{r}-V_{\text {extra-column }}\right)^{2}}{\sigma_{\text {rotor }}^{2}}
$$

eq. 3

By analogy with the height equivalent to a theoretical plate, we introduce the number of cells required to make one theoretical plate $(N C / T P)$ defined as eq.4, with $n_{c}$ being 832 cells (30-mL rotor) or 406 cells (80-mL rotor).

$$
N C / T P=\frac{n_{c}}{N_{\text {effective }}}
$$

eq.4

The resolution factor between two adjacent peaks 1 and 2, Rs, is defined as the distance between peak apexes divided by the average peak base width $\left[\left(W_{1}+W_{2}\right) / 2\right]$. Rs is calculated using eq. 5 for a fully Gaussian peak:

$$
R s=\frac{V_{R 2}-V_{R 1}}{2\left(\sigma_{2}+\sigma_{1}\right)}
$$

eq. 5

\subsection{Reproducibility}

Five analytical injections of the text mixture were done with newly equilibrated $30-\mathrm{mL}$ rotor with the same batch of Arizona N system for five successive days. The rotor spinning was $2500 \mathrm{rpm}(712 \mathrm{~g})$ and the mobile phase flow rate $9 \mathrm{~mL} / \mathrm{min}$. The relative standard deviations were $2.6 \%$ for $S f$, the stationary phase retention volume ratio, $2.9 \%$ for the coumarin dispersion, $2.1 \%$ for carvone dispersion and $1.0 \%$ for the Rs resolution factor. This reproducibility was acceptable so that, for routine control, repeated injections were intermittently and randomly performed unless, for any reason, it was found necessary.

It was feared that ethyl acetate could hydrolyze in ethanol and acetic acid upon standing after the Arizona N (HEMWat O) mixture was prepared. To ensure that the liquid biphasic system was stable in temperature and chemical composition, the partition coefficients of the two retained compounds were monitored at all time. The coumarin and carvone $K$ values were respectively $1.3 \pm 0.2$ and $7.5 \pm 0.4$, with the standard deviations being calculated for 67 experiments obtained working at 5 different centrifugal fields over four months. This test shows the high reproducibility of the CPC experiments over a long period. Ethyl acetate is mainly located in the upper phase of the selected HEMWat O (AZ N) system where it cannot hydrolyze due to water scarcity. In the aqueous lower phase, the ester hydrolysis seems hindered by the high methanol concentration (40\% v/v). No pH change of the aqueous lower phase was noted over two weeks that was however the maximum time that we set for use of a particular batch of HEMWat O (AZ N) mixture. 


\section{Results and discussion}

Modern CCC columns have a significantly better capability to retain liquid stationary

\subsection{Liquid stationary phase retention}

In hydrodynamic CCC instruments, it was demonstrated that the column acted like a constant-pressure drop pump, the stationary phase retention volume ratio $S f$ decreases linearly with the square root of flow rate [16] and in a more complex manner $S f$ depends on rotor rotation (centrifugal field) and especially tubing bore [17]. With the accurate knowledge of stationary phase retention over a wide range of operating conditions, it is possible to predict peak retention volumes and elution times.

In hydrostatic (CPC) instruments, the stationary phase retention, $S f$, does not follow the same equations. The first studies of $S f$ evolution in CPC found a direct decrease in $S f$ values with increasing flow rates, $F$. The slope of the $S f$ versus $F$ lines was not dependent on the centrifugal field for rotor rotation higher than $800 \mathrm{rpm}[18,19]$. The intercept of the $S f$ versus $F$ lines corresponded to the connecting duct volume containing only the mobile phase [18]. Later studies confirmed this trend sometimes finding change in the slope of the $S f$ versus $F$ lines at higher flow rates [11, 20, 21].

Sf versus flow rate studies

The HEMWat o (Arizona N) organic upper phase retention volume ratio was monitored at different flow rates of the aqueous lower phase in the 30-mL rotor for 5 different centrifugal fields (or forces) ranging from $112 g$ to $882 g$, i.e. rotor rotation between 1000 rpm and $2800 \mathrm{rpm}$, Table 2 (Fig. 2A). As expected, $S f$, the stationary phase retention volume ratio decreases when the mobile phase flow rate increases. However, the linear trend was not observed at any studied field and the shapes of our $S f$ versus flow rate $F$ curves differ somewhat from those obtained in similar studies [9, 12]. Taking in account that the rotary seals of our CPC unit were generating a significant amount of heat, we propose two explanations for the observed shapes of the $S f$ versus $F$ curves for the 30-mL rotor (Fig. 2A).

- At moderate centrifugal force below $400 \mathrm{~g}$, i.e. rotor rotation lower than $2000 \mathrm{rpm}$, the cooling external circulation could eliminate enough calories so that the CPC entrance was 
not heated. $S f$ decreases linearly with low flow rates as previously described [11, 18-21]. At a certain flow rate depending on the applied centrifugal force, a change of slope is observed. At $1000 \mathrm{rpm}$, with a centrifugal force of $112 \mathrm{~g}$, the initial slope is $2.8 \% /(\mathrm{mL} / \mathrm{min})$ up to $7 \mathrm{~mL} / \mathrm{min}$. At flow rates higher than $7 \mathrm{~mL} / \mathrm{min}$, the slope becomes $-6.3 \% /(\mathrm{mL} / \mathrm{min})$. It means that the first $7 \mathrm{~mL} / \mathrm{min}$ flow rate produced a $S f$ reduction of 19.6\%. However, further increasing the flow rate of the same amount, from $7 \mathrm{~mL} / \mathrm{min}(S f$ $=54 \%)$ to $14 \mathrm{~mL} / \mathrm{min}(S f=10 \%$ ), drastically reduces the $S f$ factor by more than $82 \%$ (Fig. 2A).

At $1800 \mathrm{rpm}$, the centrifugal force is three times higher: $365 \mathrm{~g}$, the initial slope is also $2.8 \% /(\mathrm{mL} / \mathrm{min})$ but keeping it up to $13 \mathrm{~mL} / \mathrm{min}$. At flow rates higher than $13 \mathrm{~mL} / \mathrm{min}$, the slope becomes $-5 \% /(\mathrm{mL} / \mathrm{min})$. A similar behavior was observed at $1000 \mathrm{rpm}$.

In previous CPC columns, flooding was observed at low rotation speed [18, 22-23]. In flooding conditions, there is a continuous leak of liquid stationary phase up to the point where it is all washed out with $S f=0$. In our case, we observe a change in slope of the $S f$ versus $F$ lines. The stationary phase $S f$ is lower than expected but still reproducible and stable over the experiment duration: there is no uninterrupted flooding.

- At high centrifugal force, i.e. rotor rotation higher than $2000 \mathrm{rpm}$, we suspect that the cooling circulating liquid was not able to completely eliminate the calories generated by the rotary seals. The entering mobile phase was heated by the rotary seal which changed the mutual solubility between the two phases of the HEMWat o (AZ N) system and completely disrupted the equilibrium at column entrance producing a lower than expected $S f$ value. As the mobile phase flow rate increases, the mobile phase itself acts as a cooling agent and the observed $S f$ becomes closer to the expected value (dotted line in Fig. 2A). Here also, it is important to note that the obtained $S f$ values were reproducible.

\section{Average linear mobile phase velocity}

In HPLC, the linear mobile phase velocity is an important parameter allowing to compare results obtained with columns of different diameters and lengths. Assuming that the CPC column can be considered as a homogeneous tube of average cross sectional area $A_{C}$, it will be possible to calculate an average linear mobile phase velocity, $u$, as the ratio of the flow rate, $F$, over $A_{C}$. It should be considered however that the liquid stationary phase occupies part of the CPC column so that the velocity, $u$, should be computed using the $S f$ factor as:

$$
u=\frac{F}{A_{C}(1-S f)}
$$

eq. 6

The average cross section of the 30-mL rotor was given by the Kromaton company as 0.018 $\mathrm{cm}^{2}$. Fig. 2B shows the $S f$ stationary phase retention volume ratio plotted versus the corresponding mobile phase velocity $u$.

The interesting result evidenced by Fig. 2B is that at moderate centrifugal force $(<400 \mathrm{~g})$ there is clearly a maximum possible mobile phase velocity explaining the slope changes seen in Fig. 2A. Fig. 2B shows that at $112 g$ (1000 rpm), the mobile phase velocity cannot exceed 9 $\mathrm{m} / \mathrm{min}$ (closed arrow in Fig. $2 \mathrm{~B}$ ) reached at $7 \mathrm{~mL} / \mathrm{min}$. At $1000 \mathrm{rpm}$ and above $7 \mathrm{~mL} / \mathrm{min}$, 
any flow rate increase is exactly compensated by a $S f$ reduction in term of velocity (eq. 6). Similarly, a maximum velocity, $u=11 \mathrm{~m} / \mathrm{min}$ (open arrow in Fig. 2B), is observed with the $365 \mathrm{~g}$ centrifugal force at $1800 \mathrm{rpm}$. This trend seems to be valid for higher centrifugal forces since a maximum velocity of $13 \mathrm{~m} / \mathrm{min}$ (blue arrow in Fig. 2B) is observed at $545 g$ (2200 $\mathrm{rpm})$. It becomes difficult to make observation at higher centrifugal forces since the theoretical linear line of $S f$ versus $F$ transposes with the 30-mL rotor in a maximum velocity $u$ of $15 \mathrm{~m} / \mathrm{min}$ (dotted lines in Fig. 2) for which there is no stationary phase left in the rotor ( $S f$ $=0$ ). Higher flow rates are technically possible, but this is no longer chromatography since there is no stationary phase to interact with the moving phase. A direct linear relationship between this observed maximum velocity and rotor rotation seems to exist as shown by the inset in Fig. 2B.

\subsection{Driving pressure}

The $S f$ study shows that the maximum centrifugal force will give the highest stationary phase retention at high flow rates needed to obtain fast separations. However CPC instruments use rotary seals with strict pressure limitation. A rotary seal is a mechanical component with a flat flanged stator, a fixed part, on which a rotating piece with flat flange fitting the stator is pressed allowing to connect a rotating tube to a motionless one. If different designs exist, rotary seals have all two inherent problems: i) the rotating part in contact with the static part generates heat, ii) above a certain pressure, the liquid inside the rotary seal can percolate between the mobile and static parts. This phenomenon is reversible, but when solvents leak in a rotary seal, they dissolve the lubricants of the ball-bearings damaging them. The rotary seals of our CPC frame could withstand pressure up to 70 bars. The working pressure was noted for all experiments and the pressure safety switch was set at 70 bars stopping automatically the pump if this limit was passed.

The experimental pressure was read when the 30-mL rotor was equilibrated at different flow rates and rotor rotation speeds. It was proposed that $\triangle P$, the CPC column driving pressure, could be expressed as:

$$
\Delta P=a . S f . \Delta \rho . \omega^{2}+b . \eta . F
$$

eq. 7

in which $\Delta \rho$ is the density difference $(\mathrm{g} / \mathrm{mL})$ between the mobile and stationary liquid phases, $\omega^{2}$ is the rotor angular velocity $\left(\mathrm{rd}^{2} / \mathrm{s}^{2}\right), \eta$ is the mobile phase viscosity (cP or Pa.s) and $a$ and $b$ are rotor related geometrical constants $[1,2,19,22]$. The first term of Eq. 7 is the hydrostatic term where pressure is generated by the centrifugal force and the two liquid phases present in the rotor cells. The second term is the pressure contribution due to the mobile phase viscosity (Darcy law). If the hydrostatic term depends on both centrifugal force and flow since $S f$ is flow related, the hydrodynamic second term depends on flow only.

From a driving pressure point of view, low mobile phase flow rates $(\mathrm{F}<5 \mathrm{~mL} / \mathrm{min}$ and high $S f$ values, Fig. 2) are not possible at fast rotor rotations: the driving pressure would pass the 70 bar rotary seal requirement. This is not a problem since low mobile phase flow rates are associated with high experiment durations and low productivity. As far as pressure is 
concerned, high mobile phase flow rates are possible at all rotor rotation speeds of our apparatus (1000-3000 rpm). The hydrodynamic viscous pressure in our experimental conditions (30-mL rotor and aqueous lower phase of the HEMWat o or AZ N system) would reach 70 bars at a flow rate of $57 \mathrm{~mL} / \mathrm{min}$. No practical experiments are possible at this high flow rate since there would be no stationary phase left in the 30-mL column (Fig. 2). At 20 $\mathrm{mL} / \mathrm{min}$, there is about $20 \%$ of stationary phase still remaining in the $30-\mathrm{mL}$ rotor for rotation higher than $2000 \mathrm{rpm}$ (Fig. 2A) and the driving pressure stays within 40-60 bars below the maximum rotary seal limit. At $20 \mathrm{~mL} / \mathrm{min}$, the $33.2 \mathrm{~mL}$ column volume is swept in $1.6 \mathrm{~min}$, a very reasonable time allowing for fast separations.

\subsection{Chromatographic efficiency}

Eq. 3 shows that the chromatographic efficiency $N$, expressed in theoretical plate number, is related to peak width. A higher efficiency produces thinner peaks increasing resolution and/or allowing higher loads in preparative purifications. Table 3 lists the full data obtained with the Fig. 1 separation examples.

In liquid chromatography with a solid stationary phase, i.e. LC techniques, $\mathrm{H}$, the height equivalent to a theoretical plate or plate height, reflects the chromatographic variance per unit length, allowing comparing efficiencies between columns of different geometries (length, diameter, particle size). Plots of $\mathrm{H}$ versus mobile phase velocity, generally referred to as van Deemter plots, are undoubtedly the most popular graphical representation of LC chromatographic performance. The plot is based on the assumption that the plate height is independent of the column length. Under similar assumption, in CPC, the number of cells equivalent to a theoretical plate, NC/TP, can be used noting that a lower NC/TP value is better.

Fig. 3 shows the rotor efficiency plotted as the number of cells equivalent to a theoretical plate $\mathrm{NC} / \mathrm{TP}$, for the two retained peaks: coumarin $(\mathrm{K}=1.3)$ and carvone $(\mathrm{K}=7.3)$ versus the mobile phase linear velocity $u$ (Figs. $3 \mathrm{~A}$ and B) and versus $S f$ the stationary phase retention volume ratio in the $30-\mathrm{mL}$ rotor (Figs. $3 \mathrm{C}$ and $\mathrm{D}$ ).

The clear trend shows by Fig. $3 \mathrm{~A}$ and $3 \mathrm{~B}$ is a significant increase in efficiency when the applied centrifugal force (rotor rotation) increases. For example, at $10 \mathrm{~m} / \mathrm{min}$ and $365 g$ (11 $\mathrm{mL} / \mathrm{min}$ and $1800 \mathrm{rpm}$ ), the NC/TPs are 1.9 and 3.5 for coumarin and carvone, respectively, corresponding to 438 and 237 plates in the $30-\mathrm{mL}$ rotor (832 cells). Working at lower centrifugal force $(112 \mathrm{~g}, 1000 \mathrm{rpm})$ has dramatic consequences, with more than 8 cells required to make one plate. A high centrifugal field is highly beneficial to the chromatographic efficiency. At $10 \mathrm{~m} / \mathrm{min}$ and $882 \mathrm{~g}$ (2800 rpm), the NC/TP is as low as 0.8 for both coumarin and carvone (corresponding to 1080 plates), demonstrating that every single cell is indeed active in the efficient mixing and resulting chromatographic exchange. Here we assume a uniform distribution of the two liquid phases throughout the CPC rotor. A reviewer pointed out that the first cells at the rotor entrance may contain less stationary phase (higher pressure) than the last cells at the rotor end (low pressure). We have no mean to check this possible dynamic state and present the average values read on the experimental chromatograms.

Figs $3 \mathrm{~A}$ and $\mathrm{B}$ show the number of cells equivalent to one theoretical plate plotted versus mobile phase velocity for the solute with low chromatographic retention (coumarin, $\mathrm{K}=1.3$, 
Fig. 3A) and the one highly retained (carvone, $\mathrm{K}=7 \cdot 3$, Fig. $3 \mathrm{~B}$ ). These plots exhibit specific shapes that are typical from chromatographic dispersions. At low mobile phase velocity, solutes are submitted to molecular diffusion both in mobile and stationary phase and the $\mathrm{NC} / \mathrm{TP}$ varies as $\frac{1}{u}$. At high mobile phase velocity, solute dispersion is mainly driven by mass transfer and highly retained compounds exhibit large band broadening $(\mathrm{NC} / \mathrm{TP}=4.8$ for carvone at $1800 \mathrm{rpm}, 11 \mathrm{~m} / \mathrm{min}$ ) while for compounds with $\mathrm{K}$ close to 1 , the linear velocity has very little influence on the NC/TP (being 2 for coumarin at $1800 \mathrm{rpm}, 11 \mathrm{~m} / \mathrm{min}$ ). These observations are very close to solute behavior in LC process (Van Deemter curves). Increasing the applied centrifugal field reduces both diffusion and mass transfer contributions to chromatographic dispersions, reaching the optimal performances of 1 cell per theoretical plate at 2500 rpm for the less retained coumarin compound and at $2800 \mathrm{rpm}$ for the more retained carvone compound.

As a consequence, it is confirmed that the best efficiencies are obtained at high rotational speed and elevated linear velocity $[1,7,8,19]$. But it is crucial to remember that, in CPC, rotation speed is constraint by pressure, while a maximum mobile phase linear velocity cannot be exceeded. Increasing the flow rate results in increasing the linear velocity up to its maximal value, but then all further flow rate increases will only reduce the working liquid stationary phase volume ratio, $S f$, being deleterious for the purification.

Fig. $3 \mathrm{C}$ and $3 \mathrm{D}$ show the same efficiencies expressed as NC/TP plotted versus the $S f$ values. The increase in efficiency as the centrifugal force increases is obviously confirmed. However, a decrease in efficiency is associated with more stationary phase in the rotor. This decrease is severe at high centrifugal forces with the less retained coumarin compound (Fig. $3 \mathrm{C})$. For example, at $882 g(2800 \mathrm{rpm})$, the coumarin NC/TP is 0.7 (1200 plates) at $S f=$ $25 \%$, reaching $\mathrm{NC} / \mathrm{TP}=1.25$ (666 plates) at $S f=33 \%$. This efficiency reduction with increased $S f$ is less severe for the more retained carvone compound (Fig. 3D) and for lower centrifugal forces. With this 30-mL rotor, working at maximal $S f$ is detrimental to efficiency.

Since the resolution factor is defined as the distance between peak apexes divided by the average peak widths (Eq. 5), it is maximized when stationary phase retention volume ratio, $S f$, is large and peak broadening is low. Thus, for low retained compounds, centrifugal forces of $2500 \mathrm{rpm}$ will provide as good a resolution as $2800 \mathrm{rpm}$, while for highly retained compounds, the increase of centrifugal force will be highly beneficial on resolution factor.

While resolution is best at low flow rate due to the large contribution of $S f$, it results in long analysis times. However, if the selectivity factor $\left(K_{2} / K_{1}\right.$ ratio) is large enough, it is worth working at higher flow rates to speed up the separations: the gain in higher throughput compensates for the loss of resolution associated with the reduced $S f$ (Fig. 2). The efficiency being higher at reduced $S f$ and high flow rates, thinner peaks should allow for increased rotor loads provided the space between peaks remains acceptable [24].

\subsection{Free space between peak and throughput estimation}

In a recent work, we proposed to use the free space between two adjacent peaks as a convenient estimate of the loading capability in a large scale rotor using the results obtained in a small CPC rotor [24]. The free space between peaks $\Delta V$ is related to the retention difference between the two peaks; that is the numerator of the resolution equation (Eq. 5). 
Since the Gaussian peak base is equal to $4 \sigma$, the free space between peaks cumulates the retention difference and the peak dispersions that are related to the denominator of the resolution equation and to efficiency (Eqs. 5 and 1).

Fig. 4A shows the experimental $\Delta V$ volume between the coumarin and carvone peaks measured in all operating conditions with the 30-mL rotor and HEMWat o (AZ N) system. The trend is an increased space between peaks when more stationary phase is in the rotor. This trend is expected since the $\Delta V$ difference is directly related to $V_{S}$. However, since $S f$ decreases with increasing flow rates (Fig. 2), it seems that it will not be possible to work with a good productivity at high flow rates. The time needed to complete the separation is a factor that must be taken in account.

Fig. $4 \mathrm{~B}$ shows the evolution of a productivity factor defined as $\Delta V / t^{\prime}{ }_{R}$, with $t_{R}^{\prime}$ being the carvone retention time (peak crest) plus two $\sigma$ (Eq. 1) corresponding to the delay needed to return to baseline. The $\Delta V / t^{\prime}{ }_{R}$ parameter gives a good idea of the throughput that will be possible to get in performing repetitive purification loads [24]. If the study confirms that a high centrifugal force (high rotor rotation) is needed to obtain a significant productivity, it shows that the maximum rotor rotation and maximum flow rate may not be necessarily the most appropriate settings to obtain the highest productivity with this particular 30-mL rotor. An optimum flow rate between 15 and $18 \mathrm{~mL}$ will give the highest productivity. We note that this optimum flow rate corresponds to the lowest flow rate giving the maximum mobile phase velocity observed in Section 3.1 and Fig. 2B. Higher flow rates deplete so much the stationary phase that the peaks cannot be enough separated. The existence of an optimal flow rate for the highest productivity was already highlighted in our previous work for GUESS compounds separation using HEMWat solvent systems on 30-mL and 259-mL rotors [24] and more recently on the 259-mL rotor for rosemary extract separation using heptane/MtBE/ ethanol/water $4: 1: 4: 1 \mathrm{v} / \mathrm{v}$ [25].

Also, in the conditions of this study, the $8 \%$ productivity gain between the highest 2800 $\mathrm{rpm}$ rotation at $18 \mathrm{~mL} / \mathrm{min}$ (open squares in Fig. 4B) and the $2200 \mathrm{rpm}$ rotation at 16 $\mathrm{mL} / \mathrm{min}$ (triangles in Fig. 4B) may not be worth the trouble and cost of more rapid rotary seal wearing.

\subsection{Working with the 80-mL rotor}

The 80-mL rotor was engineered for preparative purification at high flow rate. Compared with the 30-mL rotor, it is made with twice less cells that are almost five times bigger (Table 1) with a larger "bore" (average rotor cross section of $3.1 \mathrm{~mm}^{2}$ ) for easier liquid flowing. Considering the dedicated use of this rotor, it was studied at flow rates higher than 10 $\mathrm{mL} / \mathrm{min}$ and rotor rotations of $2200 \mathrm{rpm}, 2500 \mathrm{rpm}$ and $2800 \mathrm{rpm}$, i.e. high centrifugal forces of 545, 712 and $882 g$ (Table 2).

\section{Stationary phase retention}

Fig. 5A and 5B should be compared with Fig. 2A and 2B. The linear decrease of $S f$ is observed up to a flow rate of $33 \mathrm{~mL} / \mathrm{min}$ above which the $80-\mathrm{mL}$ rotor retains more liquid stationary phase than expected (Fig. 5A). This experimental result let us think that the cell design may allow for a small part of liquid stationary phase to be trapped and not swept by 
the mobile phase at high flow rates. The consequence is that there is no maximum linear velocity as observed with the 30 -mL rotor. Fig. $5^{\mathrm{B}}$ shows that the mobile phase linear velocity keep increasing with the flow rate up to the maximum $55 \mathrm{~mL} / \mathrm{min}$ tested, corresponding to a mobile phase velocity of $22 \mathrm{~m} / \mathrm{min}$. Higher linear velocities seem possible.

\section{Driving pressure}

The driving pressures obtained in the two rotors were compared. The trend is the same: high flow rates do not produce higher driving pressure as long as there is some liquid stationary phase remaining in the rotor. The design of the 80-mL rotor with less cells of larger volume and connecting ducts with larger bore allows running the 80-mL rotor at flow rates three times higher than what was permitted with the smaller $30-\mathrm{mL}$ rotor. Our experimental set-up was limited to a maximum flow rate of $60 \mathrm{~mL} / \mathrm{min}$. Much higher flow rates could be envisaged with the $80-\mathrm{mL}$ rotor assuming $10-12 \%$ of liquid stationary phase stay trapped in it. The hydrodynamic pressure would be the limiting factor. At $55 \mathrm{~mL} / \mathrm{min}$ and $2800 \mathrm{rpm}$, the experimental driving pressure is 31 bar well below the maximum 70 bar of the rotary seals. The observed 31 bar are made of 11 bar hydrostatic pressure (35\%, Eq. 7) and 20 bars (65\%) hydrodynamic pressure. Assuming that $10 \%$ of stationary phase stay trapped in the $80-\mathrm{mL}$ rotor $(S f=10 \%)$, Eq. 7 allows to estimate the limiting flow rate to be $170 \mathrm{~mL} / \mathrm{min}$ generating 62 bars of hydrodynamic pressure with only 8 bars due to the hydrostatic contribution at $2800 \mathrm{rpm}$.

\section{Efficiency}

Because of the lower number of cells (406 cells), the plate number is at least two times lower with the $80-\mathrm{mL}$ rotor. In order to compare instruments performances, the number of cells equivalent to one theoretical plate (NC/TP) was plotted versus mobile phase linear velocity, $u$, for the 80-mL rotor (Fig. 6 , to be compared to Fig. 3). The dispersion is driven by diffusion at low velocity, as mainly illustrated by the coumarin behavior, while the contribution to mass transfer is no longer visible, as expected by the supplier for this new design.

For compounds with low retention such as coumarin, the small rotor performs slightly better than the $80-\mathrm{mL}$ rotor when working at identical velocity. At $11 \mathrm{~m} / \mathrm{min}$ and $2800 \mathrm{rpm}$, the 30-mL rotor requires only o.6 cells to make one theoretical plate (Fig. 3A), while the 80$\mathrm{mL}$ rotor requires 1.0 cell in the same operating conditions (Fig. 6A). However, the $80-\mathrm{mL}$ rotor is designed to work faster and its performances reach $0.6 \mathrm{NC} / \mathrm{TP}$ at $20 \mathrm{~m} / \mathrm{min}$. It means that if this new design had 832 cells, it could provide the same number of plates as the $30-\mathrm{mL}$ commercial rotor (1390 plates) while working at $50 \mathrm{~mL} / \mathrm{min}$.

While the highly retained carvone NC/TP was $g$-field dependent with the small 30-mL rotor (in the range $0.8-2.7$, Fig. $3 \mathrm{~B}$ ), the $80-\mathrm{mL}$ rotor provides an efficient mixing and mass transfer for all tested centrifugal forces with carvone NC/TP in the narrow 1.5-2.0 range.

When relating the experimental efficiencies to $S f$, the ratio of stationary phase volume retained by the column, the trend of Fig. $3 \mathrm{C}$ and $3 \mathrm{D}$ was also observed with the $80-\mathrm{mL}$ rotor. Coumarin shows a regular efficiency decrease when $S f$ increases. This trend is less important for carvone whose efficiency changes were more limited. 
For the 30-mL rotor, Fig. $4 \mathrm{~A}$ shows a $\Delta V$ space between carvone and coumarin peak increasing between 20 and $120 \mathrm{~mL}$ as $S f$ increases for 10 to $70 \%$. The picture with the $80-\mathrm{mL}$ as high as $200 \mathrm{~mL}$ for $S f=60 \%$. This is illustrated by Fig. 1 showing a chromatogram done at the same 2500 rpm on the two rotors. The efficiencies obtained with the 80-mL rotor are lower meaning broader peaks in the time space shown by the figure. However, the flow rate in the $80-\mathrm{mL}$ rotor being much higher $(45 \mathrm{~mL} / \mathrm{min}$ ) compared to the $11 \mathrm{~mL} / \mathrm{min}$ in the $30-$ $\mathrm{mL}$ rotor, the $\Delta V$ space between coumarin and carvone is $88 \mathrm{~mL}$ with the $80-\mathrm{mL}$ rotor almost twice the $49 \mathrm{~mL}$ of the $30-\mathrm{mL}$ rotor (Table 3 ).

When throughput is considered introducing the time needed to complete the separation, the higher flow rates possible with the 80-mL rotor clearly shows the interest of this rotor for preparative purification. The $\Delta V / t^{\prime}{ }_{R}$ parameter obtained with the $10-55 \mathrm{~mL} / \mathrm{min}$ data of the $80-\mathrm{mL}$ rotor shows a regular increase with the flow rate, $F$. However, no maximum values as seen in Fig. 4B were obtained. The maximum theoretical productivity was seen at $17 \mathrm{~mL} / \mathrm{min}$ with a $\Delta V / t_{R}^{\prime}$ value of $6.5 \mathrm{~mL} / \mathrm{min}$ for the $30-\mathrm{mL}$ rotor (Fig. $4 \mathrm{~B}$ ). For the $80-\mathrm{mL}$ rotor, the highest theoretical productivity was obtained at the maximum flow rate tested, $55 \mathrm{~mL} / \mathrm{min}$, with a $\Delta V / t_{R}^{\prime}$ value of $18 \mathrm{~mL} / \mathrm{min}$. Higher flow rates are possible and would give better productivity. The three $\Delta V / t^{\prime}{ }_{R}$ versus $F$ lines obtained with the three rotor rotations tested were similar. This indicates that, in our particular experimental conditions, it is best to work at $2200 \mathrm{rpm}$ reducing strain and wearing of the equipment, still obtaining the best productivity.

\section{Conclusion}

Using a simple separation of test solutes and working only at analytical concentrations with a small $30-\mathrm{mL}$ rotor and a larger $80-\mathrm{mL}$ rotor of different configuration, a large set of operating conditions was tested with the heptane/ethyl acetate/methanol/water 1:1:1:1 v/v HEMWat zero or Arizona N system. It is confirmed that the amount of liquid stationary phase retained in the rotor decreases linearly when the flow rate of the mobile phase increases. In our experimental conditions, a maximum linear velocity of the mobile phase was observed with the 30-mL rotor: in a given centrifugal force (rotor speed), the mobile phase cannot pass a maximum linear velocity. When this maximum velocity is reached, increasing the flow rate will just deplete the stationary phase so that the linear mobile phase velocity stays the same, up to a complete washing of all stationary phase off the rotor.

The 80-mL rotor exhibits the same stationary phase retention decreasing linearly with flow rate increases. However, this trend was somehow stopped above $35 \mathrm{~mL} / \mathrm{min}$, where it was observed that the mobile phase flow could not expel 10 to $15 \%$ of the stationary phase contained in the rotor making separations possible at very high flows.

The study of the experimental chromatographic efficiency was performed using the concept of NC/TP: number of cells needed to make one theoretical plate, as representative of peak width. It is confirmed with the two rotors that a higher centrifugal force (higher rotor 
rotation) and higher flow rates produced sharper peaks (more plates). However, when preparative purifications are the goal of the CPC separation, it was shown that an optimum flow rate for best throughput existed with the 30-mL rotor. This optimum could not be reached with the 80-mL rotor due to hardware limitation.

This attempt of generic column characterization should of course be taken with care as it is solvent system- and rotor design-dependent. From a user's perspective, the sample to purify should be considered. Selecting a liquid system in which the compound to purify is well separated from impurities, being significantly retain (e.g. $\mathrm{K}>5$ ), it may be of interest to work at high flow rate with an optimized amount of stationary phase. A prejudice would be to think that working at the highest stationary phase retention (i.e. the highest rotor rotation) provides the best results. On the contrary, it often leads to unnecessary long separations and broad peaks, damaging the reputation of the CPC technique.

\section{Acknowledgements}

$\mathrm{AB}$ and $\mathrm{KF}$ thanks the French Centre National de la Recherche Scientifique for continuous support through ISA-UMR 5280. KF thanks the Rousselet-Robatel Kromaton company for the loan of the 80-mL rotor prototype.

\section{References}

[1] A.P. Foucault, Centrifugal Partition Chromatography, Chromatogr. Sci. Ser., vol. 68, M. Dekker, New York, 1992.

[2] A. Berthod, Countercurrent chromatography: the support-free liquid stationary phase, Comprehensive Analytical Chemistry, vol. 38, Elsevier, 2002.

[3] Y. Ito, W.D. Conway, High-Speed Countercurrent Chromatography, Chemical Analysis, J. Wiley, 1996.

[4] K. Skalicka-Wozniak, I. Garrard, A comprehensive classification of solvent systems used for natural product purifications in countercurrent and centrifugal partition chromatography, Nat. Prod. Rep., 32 (2015) 1556-1561.

[5] Y. Liu, J.B. Friesen, J.B. McAlpine, G.F. Pauli, Solvent system selection strategies in countercurrent separation, Planta Medica, 81 (2015) 1582-1591.

[6] Y. Ito, Golden rules and pitfalls in selecting optimum conditions for high-speed counter-current chromatography, J. Chromatogr. A, 1065 (2005) 145-168.

[7] L. Marchal, A. Foucault, G. Patissier, J.M. Rosant, J. Legrand, Influence of flow patterns on chromatographic efficiency in centrifugal partition chromatography, $\mathrm{J}$. Chromatogr. A, 869 (2000) 339-352.

[8] L. Marchal, J. Legrand, A. Foucault, Mass transport and flow regimes in centrifugal partition chromatography, AIChE J. 48 (2002) 1692-1704.

[9] S. Chollet, L. Marchal, J. Meucci, J.H. Renault, J. Legrand, A. Foucault, Methodology for optimally sized centrifugal partition chromatography columns, J. Chromatogr. A, 1388 (2015) 174-183. 
[10] S. Adelmann, C. Schwienheer, G. Schembecker, Multiphase flow modeling in centrifugal partition chromatography, J. Chromatogr. A, 1218 (2011) 6092-6101.

[11] S. Adelmann, G. Schembecker, Influence of physical properties and operating parameters on hydrodynamics in centrifugal partition chromatography, J. Chromatogr. A, 1218 (2011) 5401-5413.

[12] C. Schwienheer, J. Merz, G. Schembecker, Investigation, comparison and design of chambers used in centrifugal partition chromatography on the basis of flow pattern and separation experiments, J. Chromatogr. A, 1390 (2015) 39-49.

[13] A. Berthod, M. Hassoun, M.J. Ruiz-Angel, Alkane effect in the Arizona liquid systems used in countercurrent chromatography, Anal. Bioanal. Chem., 383 (2005) 327-340.

[14] J.B. Friesen, G.F. Pauli, GUESS - A generally useful estimate of solvent system in CCC, J. Liq. Chromatogr. Rel. Technol, 28 (2005) 2777-2806.

[15] J.B. Friesen, G.F. Pauli, Rational development of solvent system families in CCC, J. Chromatogr. A, 1151 (2007) 51-59.

[16] P.L. Wood, D. Hawes, L. Janaway, I.A. Sutherland, Stationary phase retention in CCC: modeling the J-type centrifuge as a constant pressure drop pump, J. Liq. Chromatogr. Rel. Technol. 26 (2003) 1373-1396.

[17] A. Berthod, K. Faure, Revisiting resolution in hydrodynamic countercurrent chromatographic: tubing bore effect, J. Chromatogr. A, 1390 (2015) 71-77.

[18] A.P. Foucault, O. Bousquet, F. Le Goffic, J. Cazes, Countercurrent chromatography with a new centrifugal partition chromatographic system, J. Liq. Chromatogr. 15 (1992) 2721-2733.

[19] A. P. Foucault, Theory of centrifugal partition chromatography, in Centrifugal Partition Chromatography, A.P. Foucault, ed., Chromatogr. Sci. Ser., Vol. 68, Ch. 2, 25-49, 1992.

[20] A. Kotland, S. Chollet, J.M. Autret, C. Diard, L. Marchal, J.H. Renault, Modeling pHzone refining CCC: a dynamic approach, J. Chromatogr. A, 1391 (2015) 80-87.

[21] S. Adelmann, T. Baldhoff, B. Koepcke, G. Schembecker, Selection of operating parameters on the basis of hydrodynamics in centrifugal partition chromatography for the purification of nybomycin derivatives, J. Chromatogr. A 1274 (2013) 54-64.

[22] D.W. Armstrong, G.L. Bertrand, A. Berthod, Study of the origin and mechanism of band broadening and pressure drop in centrifugal countercurrent chromatography, Anal. Chem. 60 (1988) 2513-2519.

[23] L. Marchal, O. Intes, A.P. Foucault, J. Legrand, J.M. Nuzillard, J.H. Renault, Rational improvement in CPC settings for the production of 5 - $n$-alkylresorcinols from wheat bran lipid extract: I. Flooding conditions-optimizing the injection step, J. Chromatogr. A 1005 (2003) 51-62.

[24] E. Bouju, A. Berthod, K. Faure, Scale-up in CPC: the "free-space between peaks" method, J. Chromatogr. A 1409 (2015) 70-78.

[25] E. Bouju, A. Berthod, K. Faure, Carnosol purification. Scaling-up centrifugal partition phromatography separations, J. Chromatogr. A in press http://dx.doi.org/10.1016/j.chroma.2016.08.015 2016. 
Table 1: Characteristics of the two tested CPC rotors.

694

\begin{tabular}{|c|c|c|c|c|c|c|c|}
\hline $\begin{array}{c}\text { Rotor } \\
\text { denomination }\end{array}$ & $\begin{array}{c}\text { Measured } \\
\text { volume } \\
\mathrm{mL}\end{array}$ & $\begin{array}{c}\text { Cell } \\
\text { number }\end{array}$ & Cell shape & $\begin{array}{c}\text { Cell } \\
\text { volume } \\
\mu \mathrm{L}\end{array}$ & $\begin{array}{c}\text { Total duct } \\
\text { volume } \\
\mathrm{mL}\end{array}$ & $\begin{array}{c}\text { Maximum } \\
S f^{*}\end{array}$ & $\begin{array}{c}\text { Total cell } \\
\text { volume } \\
\mathrm{mL}\end{array}$ \\
\hline $\mathbf{3 0 - m L}$ & 33.25 & 832 & $\begin{array}{c}\text { Twin } 8 \\
\text { shaped }\end{array}$ & 30 & 8.3 & $74.9 \%$ & 24.9 \\
\hline $\mathbf{8 0}-\mathbf{m L}$ & 83.4 & 406 & $\begin{array}{c}\text { Twin } \\
\text { proprietary }\end{array}$ & 144 & 25.0 & $70.0 \%$ & 58.4 \\
\hline
\end{tabular}

695

696

697

698

699

700

701

702

703

704

705

${ }^{*}$ Twin-cells are interconnected by duct canals that can contain mobile phase only, hence there is a maximum theoretical $S f$ corresponding to all twin-cells filled by stationary phase.

Table 2: Centrifugal fields generated by different rotation speeds for the two CPC rotors with an average $10-\mathrm{cm}$ distance of the cells from the axis of rotation.

\begin{tabular}{|c|c|c|c|c|c|}
\hline $\begin{array}{c}\text { Rotation speed } \\
(\mathrm{rpm})\end{array}$ & 1000 & 1800 & 2200 & 2500 & 2800 \\
\hline $\begin{array}{c}\text { Angular velocity } \\
(\omega, \mathrm{rd} / \mathrm{s})\end{array}$ & 105 & 188 & 230 & 262 & 293 \\
\hline $\begin{array}{c}\text { Centrifugal field } \\
\left(g^{\mathrm{a}}\right)\end{array}$ & 112 & 365 & 545 & 712 & 882 \\
\hline
\end{tabular}

a) $g$ is the earth average gravitational field equal to $9.81 \mathrm{~m} / \mathrm{s}^{2}$ 
Table 3 : Data corresponding to the Fig. 1 chromatogram.

\begin{tabular}{|c|c|c|c|}
\hline Parameter / Compounds & $\begin{array}{l}\text { New coccine } \\
\text { red }\end{array}$ & Coumarin & Carvone \\
\hline \multicolumn{4}{|l|}{ Rotor 30-mL } \\
\hline$t_{R}(\min )$ & 2.52 & 3.70 & 9.53 \\
\hline $\mathrm{V}_{\mathrm{R}}(\mathrm{mL})$ & 27.7 & 40.7 & 104.8 \\
\hline Calculated K & 0 & 1.25 & 7.41 \\
\hline Peak width at $1 / 2 \mathrm{~h}(\mathrm{~mL})$ & 2.2 & 3.6 & 11.5 \\
\hline N observed (plates) & 900 & 720 & 460 \\
\hline N effective (plates) & - & 1030 & 480 \\
\hline Cells for one theoretical plate & & 0.8 & 1.7 \\
\hline$\Delta \mathrm{V}(\mathrm{mL})$ & \multicolumn{2}{|c|}{7} & \\
\hline$\Delta \mathrm{V} / \mathrm{t}^{\prime}(\mathrm{mL} / \mathrm{min})$ & 1.8 & & \\
\hline \multicolumn{4}{|l|}{ Rotor 80-mL } \\
\hline$t_{R}(\min )$ & 1.53 & 2.07 & 4.78 \\
\hline $\mathrm{V}_{\mathrm{R}}(\mathrm{mL})$ & 68.9 & 93.1 & 215 \\
\hline Calculated K & $\mathrm{O}$ & 1.24 & 7.49 \\
\hline Peak width at $1 / 2 \mathrm{~h}(\mathrm{~mL})$ & 5.7 & 8.9 & 30.9 \\
\hline N observed (plates) & 800 & 610 & 270 \\
\hline $\mathrm{N}$ effective (plates) & & 680 & 275 \\
\hline Cells for one theoretical plate & & 0.6 & 1.5 \\
\hline$\Delta \mathrm{V}(\mathrm{mL})$ & \multicolumn{2}{|c|}{9.5} & \\
\hline$\Delta \mathrm{V} / \mathrm{t}^{\prime}(\mathrm{mL} / \mathrm{min})$ & & & \\
\hline \multicolumn{2}{|l|}{ CPC conditions and rotor data } & $30 \mathrm{~mL}$ & $80 \mathrm{~mL}$ \\
\hline \multirow{10}{*}{$\begin{array}{c}\text { 30-mL top chromatogram } \\
80-m L \text { bottom } \\
\text { chromatogram }\end{array}$} & $\begin{array}{l}\text { Rotation (rpm) } \\
\text { Centrifugal } \\
\text { force }\end{array}$ & $\begin{array}{l}2500 \\
712 \mathrm{~g}\end{array}$ & $\begin{array}{l}2500 \\
712 \mathrm{~g}\end{array}$ \\
\hline & $\begin{array}{l}\text { Flow rate } \\
(\mathrm{mL} / \mathrm{min})\end{array}$ & 11 & 45 \\
\hline & $\mathrm{V}_{\mathrm{C}}(\mathrm{mL})$ & 33.2 & 83.4 \\
\hline & $\begin{array}{l}\text { Average cross } \\
\text { section }\left(\mathrm{mm}^{2}\right)\end{array}$ & 1.8 & 3.1 \\
\hline & $\begin{array}{l}\text { Extra-column } \\
\text { volume }(\mathrm{mL})\end{array}$ & 4.9 & 4.9 \\
\hline & $\mathrm{V}_{\mathrm{M}}(\mathrm{mL})$ & 27.7 & 68.9 \\
\hline & $\mathrm{V}_{\mathrm{S}}(\mathrm{mL})$ & 10.4 & 19.5 \\
\hline & $\mathrm{Sf}$ & $31.3 \%$ & $23.4 \%$ \\
\hline & $\begin{array}{l}\text { Linear velocity } \\
(\mathrm{m} / \mathrm{min})\end{array}$ & 9 & 19.5 \\
\hline & Pressure (bar) & 51 & 32 \\
\hline
\end{tabular}




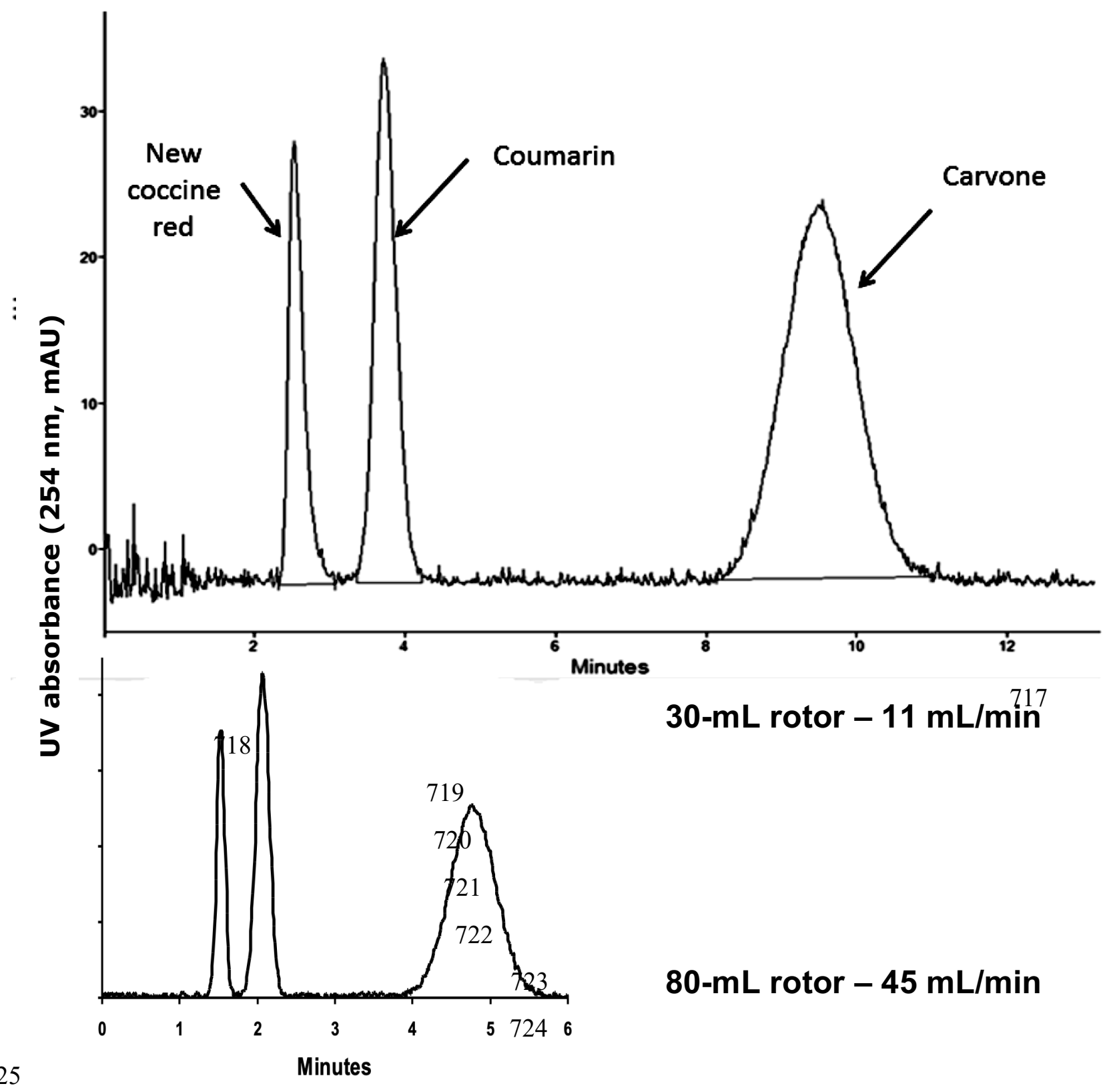

Figure 1. Chromatograms of new coccine red (0.25 mg), coumarin (0.75 mg) and carvone (1.25 mg) separated with the liquid system HEMWat O (Arizona N): heptane/ethyl acetate/methanol/water 1:1:1:1 v/v, descending mode. Injection volume $0.5 \mathrm{~mL}$. Top: column 30-mL rotor, flow rate: $11 \mathrm{~mL} / \mathrm{min}, 712 \mathrm{~g}(2500 \mathrm{rpm}), V_{M}=27.7 \mathrm{~mL}$, stationary phase retention (volume ratio) $S f=31.3 \%, 51$ bar, UV $254 \mathrm{~nm}$. Bottom: column 80-mL, flow rate: $45 \mathrm{~mL} / \mathrm{min}, 712 \mathrm{~g}(2500 \mathrm{rpm}), V_{M}=68.8 \mathrm{~mL}$, stationary phase retention volume ratio $S f=23.4 \%, 32$ bar, UV $254 \mathrm{~nm}$. See Table 3 for full experimental details. 


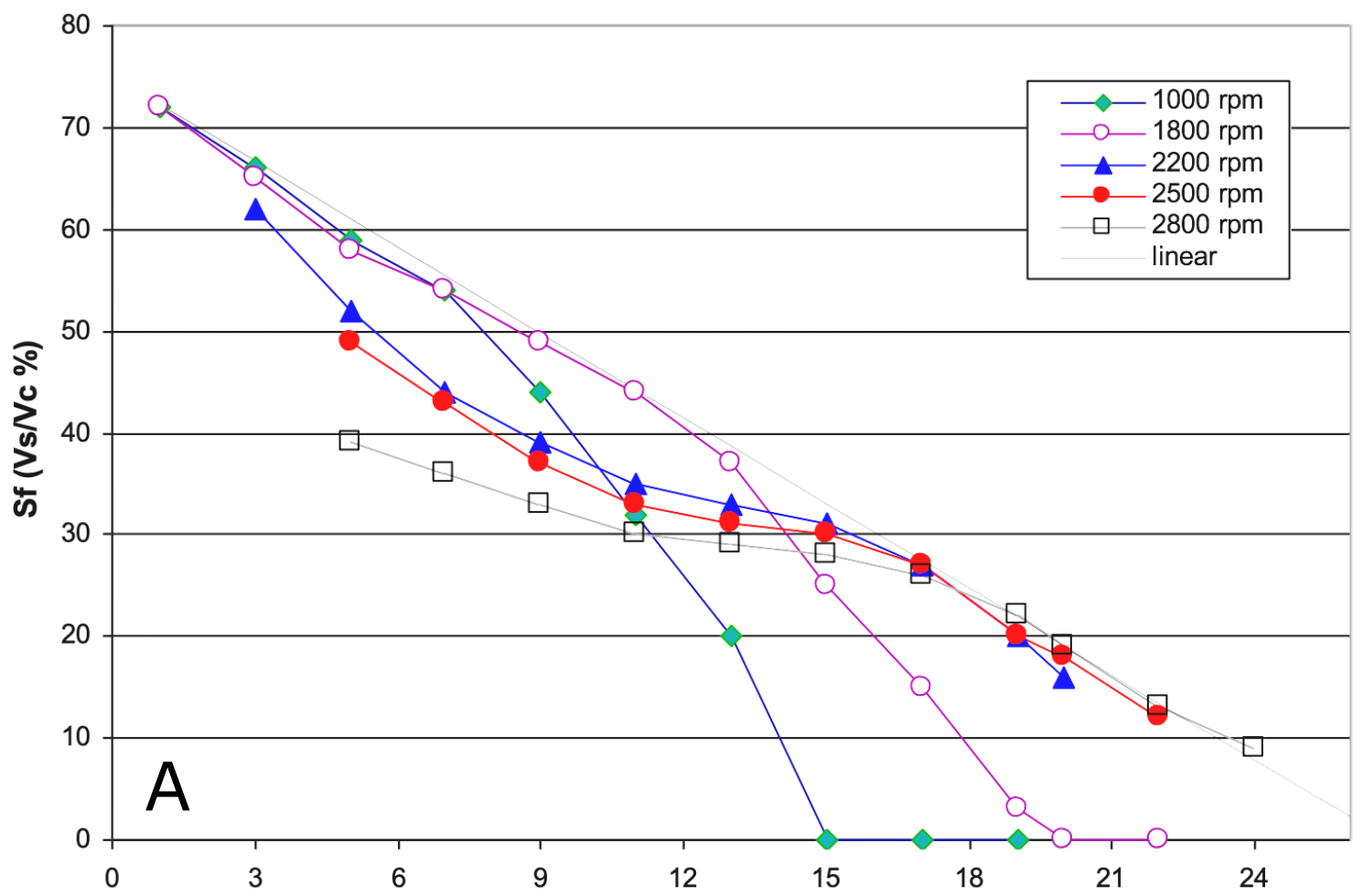

Flow rate (mL/min)

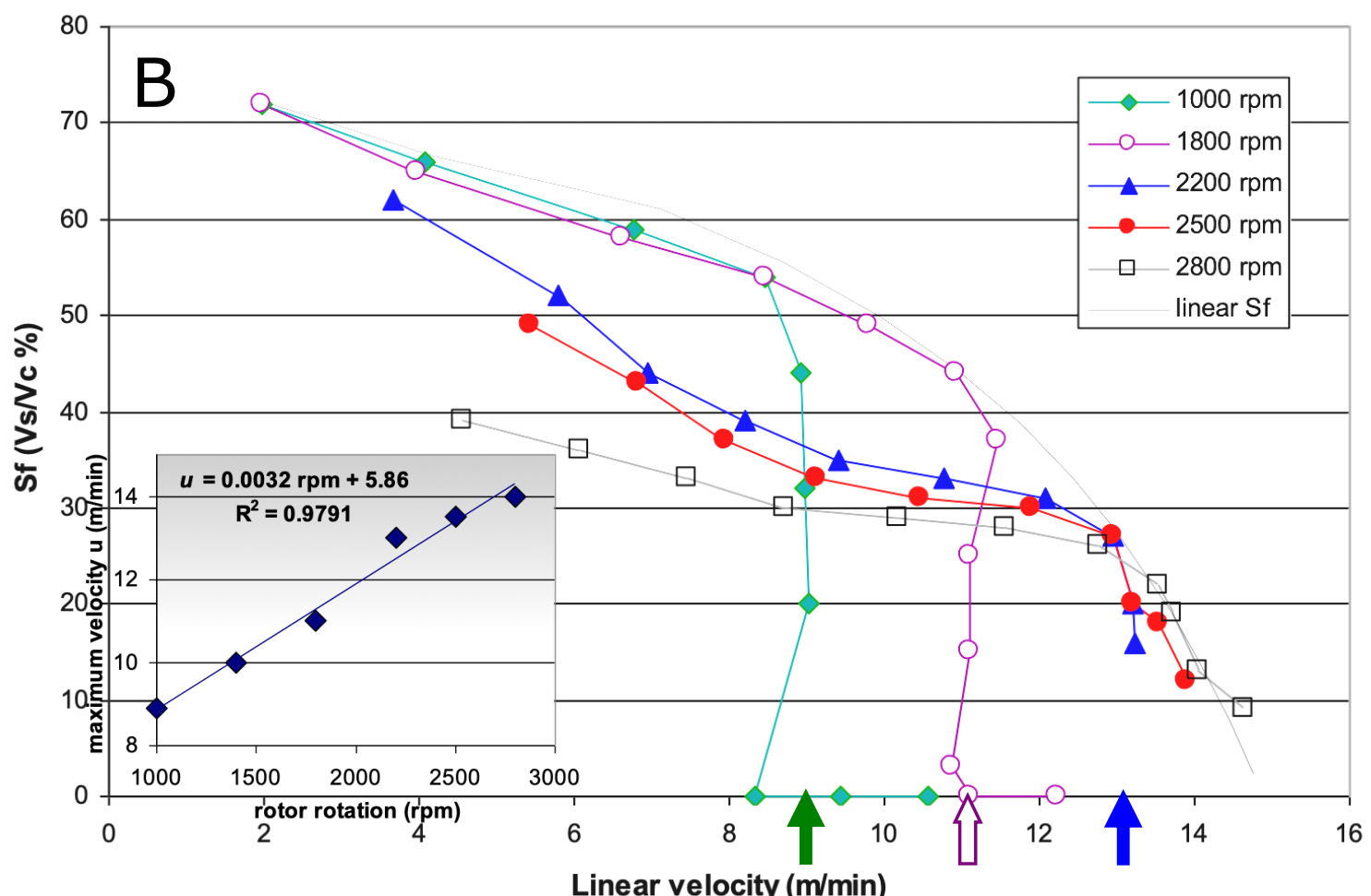

Figure 2. Organic upper stationary phase retention (volume ratio), $S f$, versus A-the aqueous mobile phase flow rate $(\mathrm{mL} / \mathrm{min})$ and $\mathbf{B}$-the aqueous mobile phase velocity $(\mathrm{m} / \mathrm{min})$ at different $30-\mathrm{mL}$ rotor rotations. The dotted lines correspond to the linear relation: $S f=$ $75 \%-2.8 F(2 \mathrm{~A})$ transposed by eq. 4 in $2 \mathrm{~B}$. The arrows point at maximum velocities. The lower left inset shows the maximum velocities plotted versus rotor rotation. 

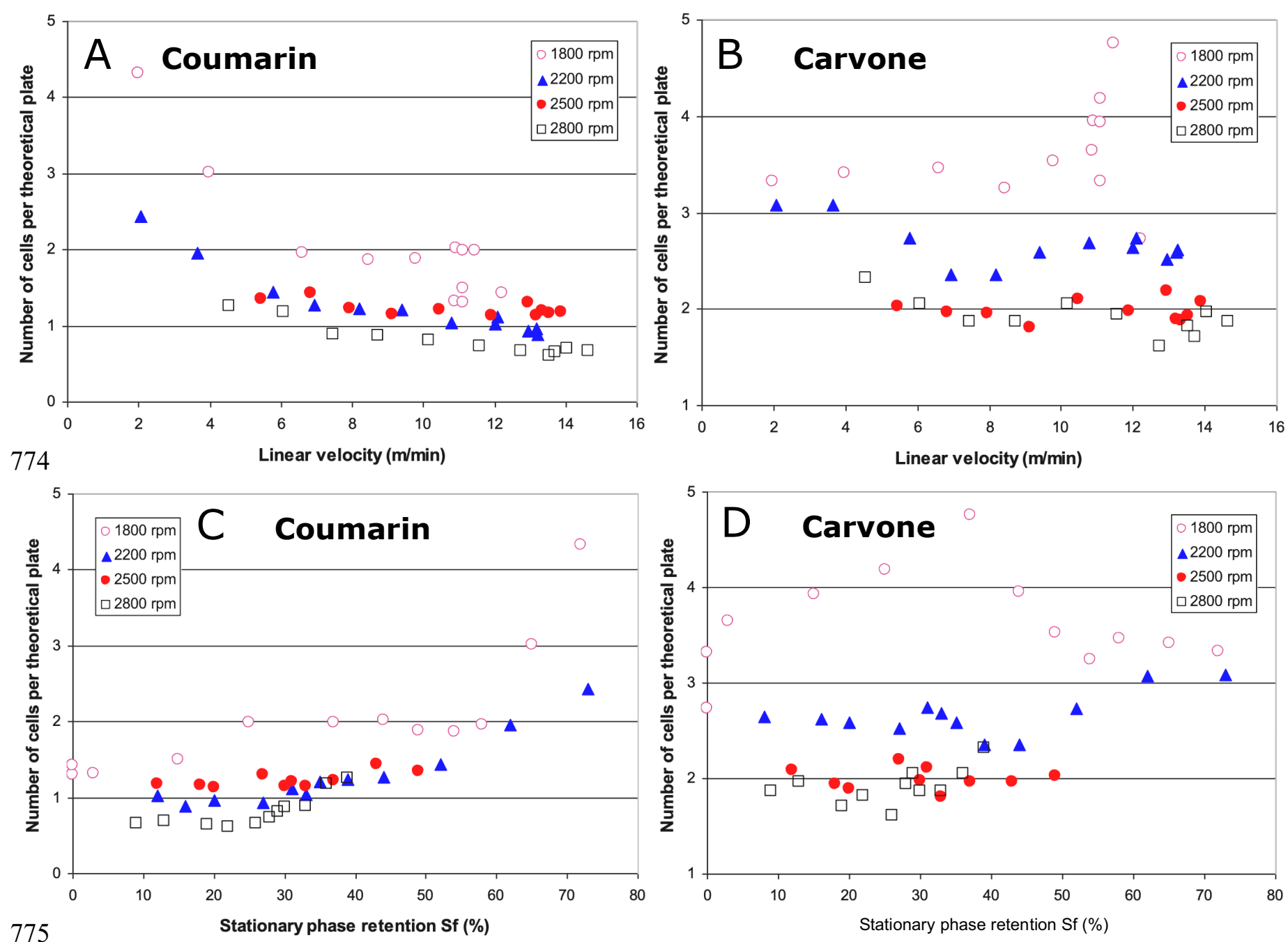

776

777

Figure 3. Coumarin (left) and carvone (right) peak experimental efficiency expressed as

778 the number of cells needed for one theoretical plate (NC/TP, lower is better) plotted versus

779 the mobile phase linear velocity (top figures A and B) and Sf, the volume ratio of stationary

780 phase retained in a 30-mL CPC rotor (bottom figures $\mathrm{C}$ and $\mathrm{D}$ ) spinning at indicated rotation

781 speeds. Rotor of 832 twin-cells. System HEMWat o (AZ N) heptane/ethyl

782 acetate/methanol/water 1:1:1:1 v/v, aqueous lower phase in the descending mode. 


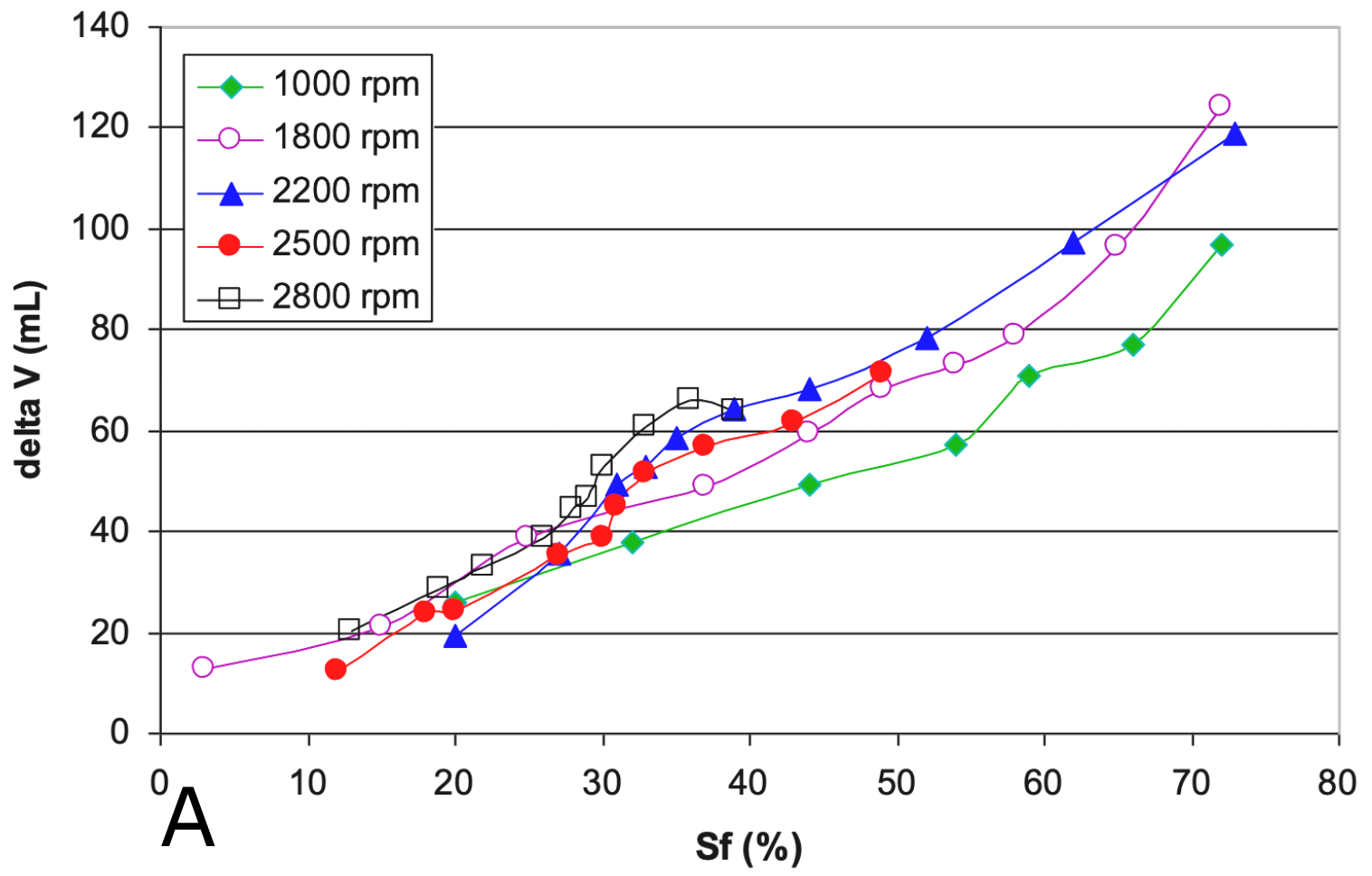

813

Figure 4. A- Free-space between coumarin and carvone peaks $\Delta V$ as a function of $S f$. B-

815 Productivity expressed as the $\Delta V / t$ ratio plotted versus mobile phase flow rate at different $30-$ 816 mL rotor rotations.

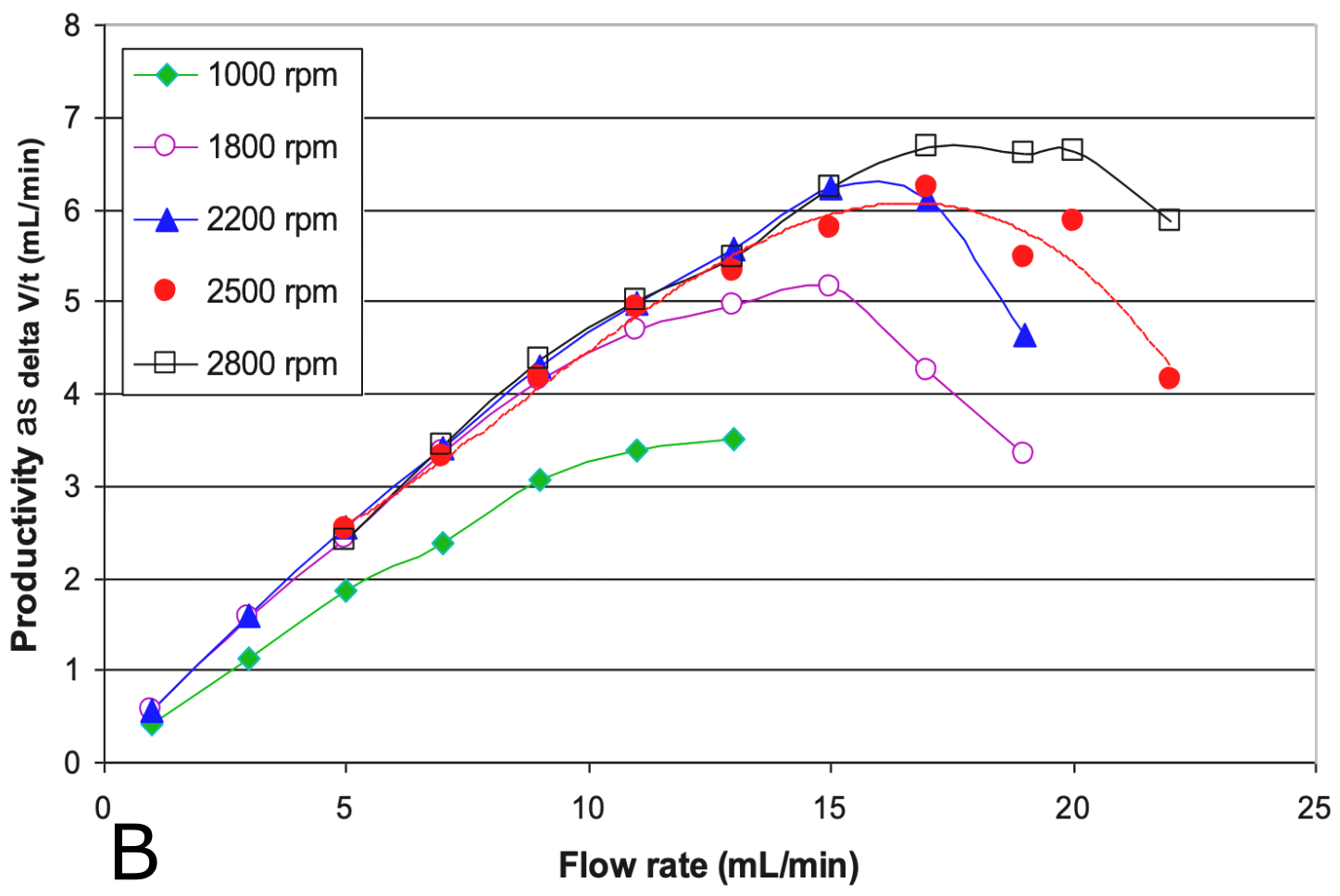




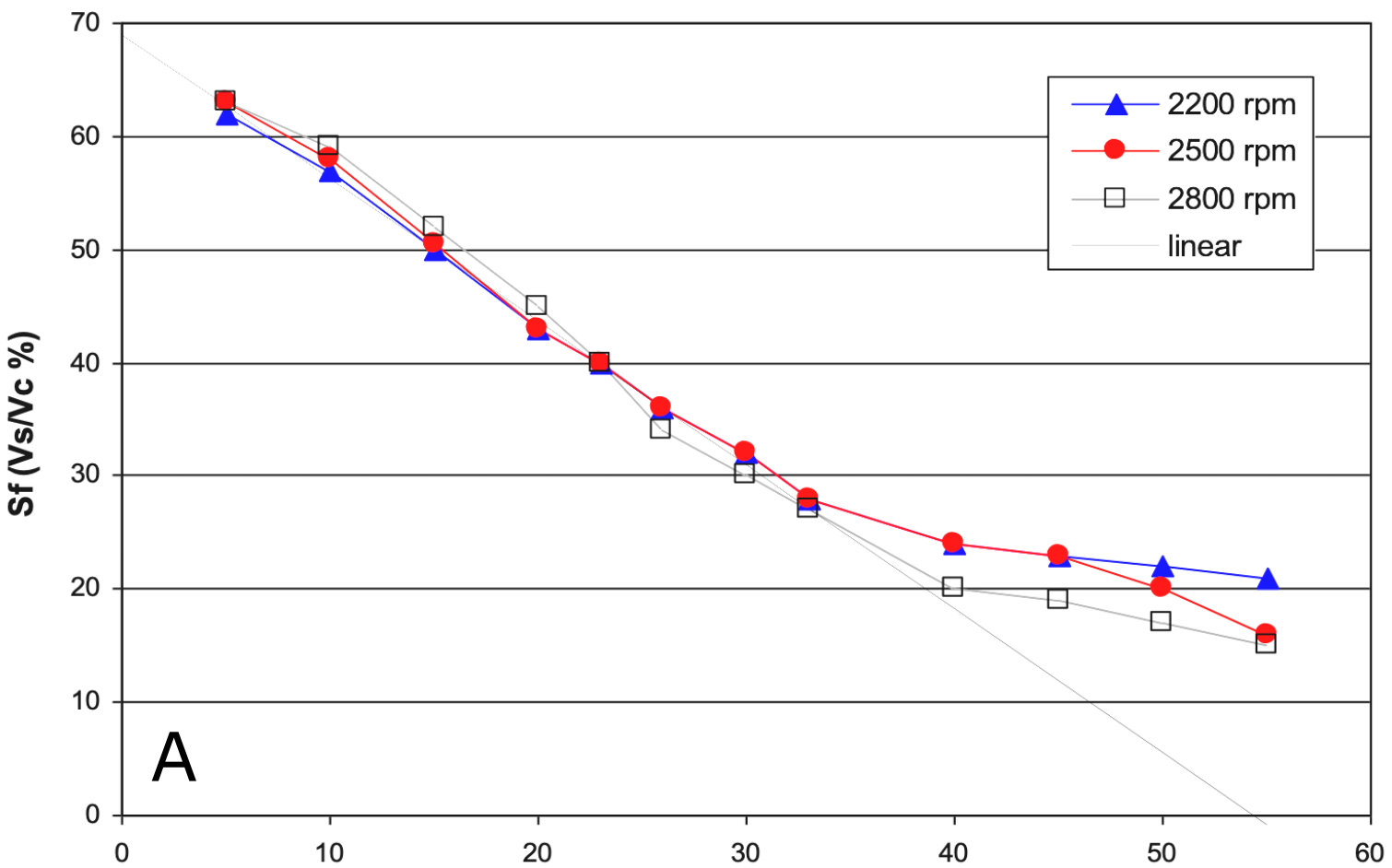

.
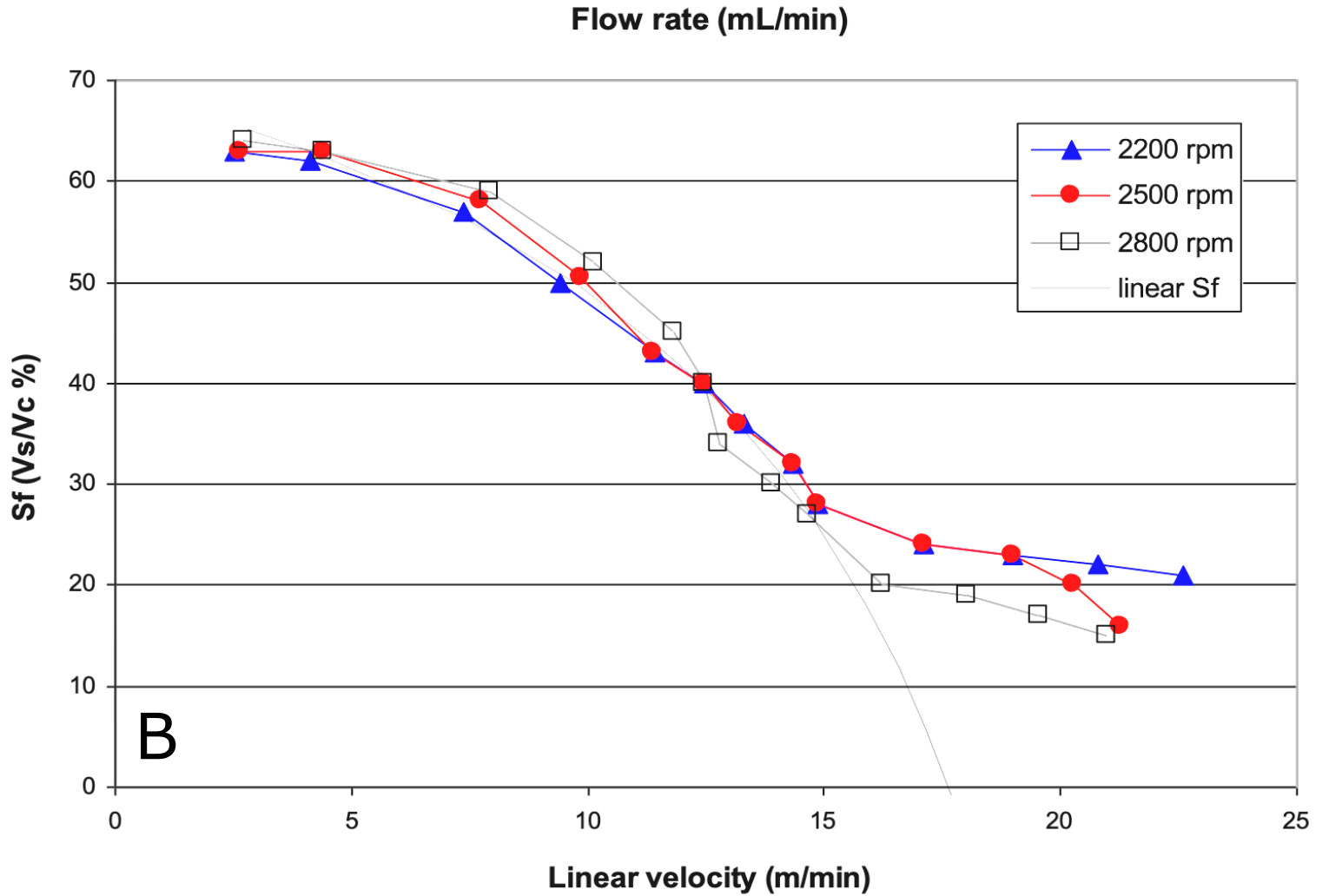

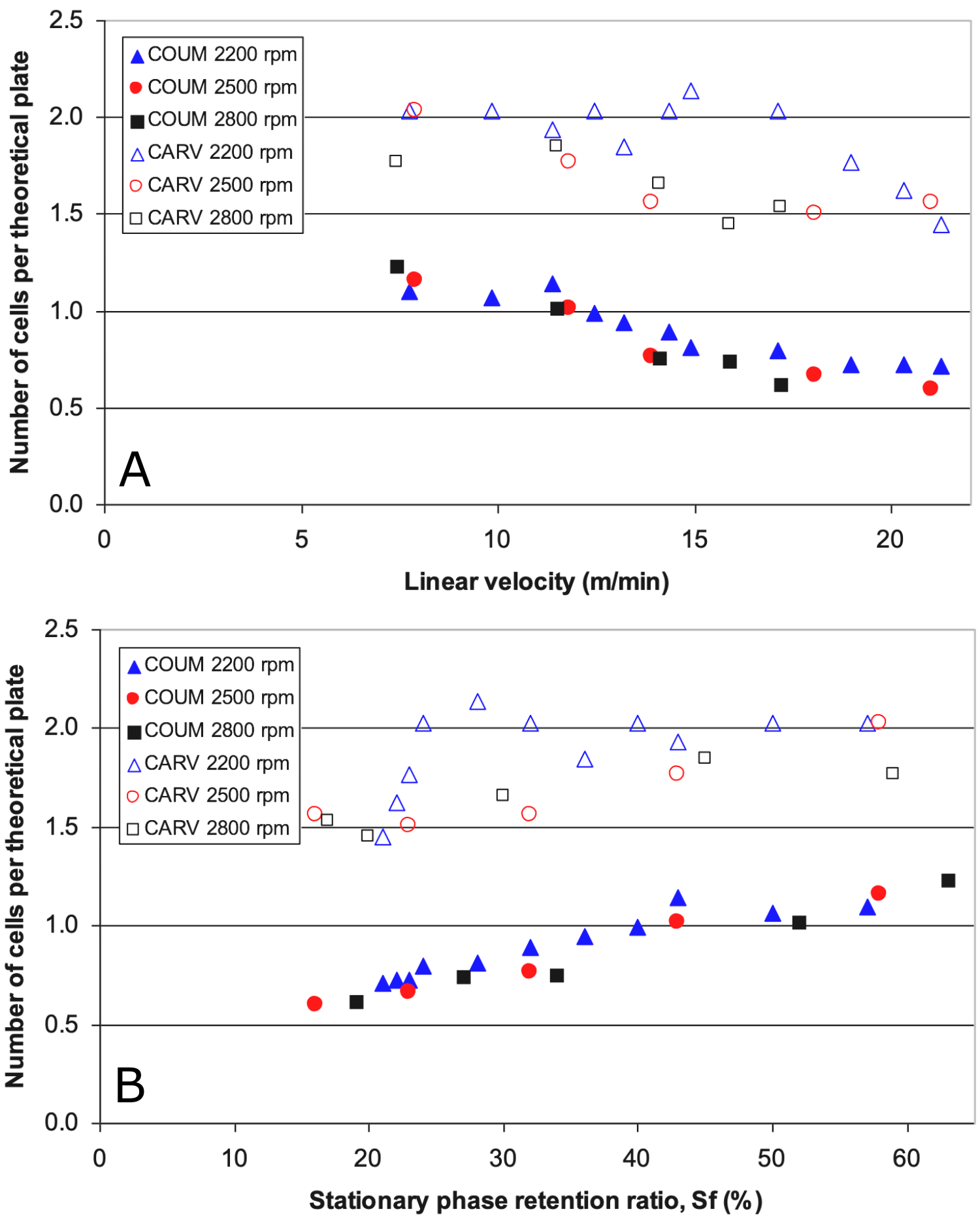

Figure 6. Coumarin (closed marks) and carvone (open marks) peak experimental efficiency expressed as the number of cells needed for one theoretical plate (NC/TP) plotted versus A: the mobile phase linear velocity and $\mathbf{B}$ : Sf, the volume ratio of stationary phase retained in the $80-\mathrm{mL}$ CPC rotor spinning at indicated rotation speeds. System HEMWat o $(\mathrm{AZ} \mathrm{N})$ heptane/ethyl acetate/methanol/water 1:1:1:1 v/v, aqueous lower phase in the descending mode. Compare with Fig. 3 for 30-mL rotor. 